\title{
Formas de preparo de solo e controle de plantas daninhas nos fatores agronômicos e de produção da mandioca
}

\section{Forms of soil tillage and weed control in agronomic factors and production of cassava}

\author{
Auro Akio Otsubo ${ }^{1 *}$; Osmar Rodrigues Brito ${ }^{2}$; Daniel Pires Passos ${ }^{3}$; \\ Humberto Sampaio de Araujo ${ }^{4}$; Fábio Martins Mercante ${ }^{1}$; Victor Hugo Nakase Otsubo ${ }^{5}$
}

\section{Resumo}

O trabalho foi conduzido com o objetivo de avaliar formas de preparo de solo e o controle de plantas daninhas sobre a produção da mandioca. Anteriormente ao plantio do experimento, deixou-se uma área em pousio, com predominância de Brachiaria brizantha, e em outra área, cultivou-se aveia preta em sistema convencional de preparo de solo. Ao final do ciclo da aveia a área foi utilizada para instalação do experimento com a cultura da mandioca (cv IAC15). O delineamento experimental foi o de blocos casualizados com três tratamentos e seis repetições. Os tratamentos testados correspondentes aos tipos de preparo do solo e sistemas de condução da lavoura foram os seguintes: T1- preparo convencional do solo na área em pousio e com controle de plantas daninhas (PC), T2 - Plantio direto sobre a palhada de aveia sem controle das plantas invasoras (PDsc) e T3 - Plantio direto sobre a palhada de aveia com controle das plantas invasoras (PDcc). Para o tratamento correspondente ao preparo convencional (PC) as parcelas experimentais foram preparadas com uma aração e uma gradagem niveladora. $\mathrm{O}$ plantio direto foi realizado utilizando plantadora mecanizada. A colheita foi realizada 14 meses após o plantio. Os maiores valores para altura de plantas e massa fresca da parte aérea foram observados nos tratamentos correspondentes ao sistema de plantio direto na palha (PD-sc e PD-cc). O maior número de raízes ha-1 foi obtido no tratamento PD-sc que diferiu somente do PC. Não foram observadas diferenças significativas para a produção de massa fresca de raízes entre os tratamentos testados. Quanto ao teor de amido das raízes o maior valor foi obtido no tratamento PD-cc.

Palavras-chave: Manihot esculenta, cobertura vegetal, plantio direto, cultivo mínimo

\begin{abstract}
The study was conducted to evaluate ways of soil tillage and weed control on the production of cassava. Prior to planting the experiment, an area was left fallow, with a predominance of Brachiaria brizantha, and another area cultivated oat in the conventional tillage system. At the end of the cycle of oats the area was used for the experiment with cassava (cv IAC15). The experimental design was a randomized complete block with three treatments and six repetitions. The treatments corresponding to the types of tillage systems and crop driving were: T1-conventional tillage in the fallow and weed control (CT), T2 - No-till on the oat stubble without control of invasive plants (NTwwc) and T3 - No-till oat straw on the
\end{abstract}

1 Eng ${ }^{\circ} \mathrm{Agr}^{\circ}$, Dr. Pesquisador da Embrapa Agropecuária Oeste, Dourados, MS. E-mail: auro.ao@hotmail.com; mercante@cpao. embrapa.br

2 Prof. Dr. do Dept ${ }^{\circ}$ de Agronomia da Universidade Estadual de Londrina, UEL, Londrina, PR. E-mail: osmar@uel.br

3 Eng ${ }^{\circ}$ Agr ${ }^{\circ}$, da AESCA, Dourados, MS. E-mail: dnp.passos@yahoo.com.br

${ }^{4}$ Eng $^{\text {O Agr }}{ }^{\circ}$, M.Sc, Pesquisador da APTA-Polo Regional Alta Sorocabana, Presidente Prudente, SP. E-mail: humbertosaraujo@ apta.sp.gov.br

5 Eng ${ }^{\circ}$ Agr ${ }^{\circ}$, UEL, Londrina, PR. E-mail: victorotsubo@gmail.com

* Autor para correspondência 
control of invasive plants (NTwc). For the treatment corresponding to conventional tillage (CT) of the experimental plots were prepared with a plow and a harrow leveling. The tillage was performed using mechanized planter. The harvest was performed 14 months after planting. The highest values for plant height and fresh weight of shoots were observed in treatments corresponding to the no-tillage system (NTwc and NTwwc). The greatest number of roots ha ${ }^{-1}$ was observed in NTwwc treatment differing only from the CT. No significant differences were observed for the fresh mass production of roots among the treatments. The highest value from starch content of roots obtained was in the NTwc treatment.

Key words: Manihot esculenta, cover crops, tillage systems, minimum tillage

(CONTI; FEY, 2007) e a redução da erosão hídrica

O objetivo do preparo do solo é o de disponibilizar água, nutrientes e eliminar a concorrência de determinadas plantas (SOUZA et al., 2007), sendo o mais comum para o cultivo da mandioca (Manihot esculenta Crantz) a utilização de uma aração e duas gradagens (GABRIEL FILHO et al., 2000), o que pode trazer problemas de compactação, erosão, empobrecimento do solo e conseqüente queda no rendimento dos cultivos. Como alerta Lorenzi e Dias (1993), a mandioca é uma cultura que deixa o solo desprotegido por um longo período, especialmente no primeiro ciclo vegetativo. $\mathrm{O}$ plantio realizado em período chuvoso, com o solo preparado e descoberto, pouca cobertura inicial do solo pela planta, que emerge muito lentamente e a colheita que, na maioria das vezes, também é realizada em período chuvoso e que revolve o solo uma segunda vez, deixando-o novamente exposto, além do cultivo em áreas declivosas, sem adoção de práticas conservacionistas, tem sido citados por Souza, Souza e Gomes (2006) como fatores inerentes da cultura que potencializam os efeitos negativos dos processos de erosão.

O processo erosivo do solo, em áreas cultivadas, é afetado por dois aspectos: o uso e o manejo. Os riscos de erosão são minimizados quando o solo é usado conforme sua capacidade. Já o manejo consiste em trabalhar o solo de maneira a torná-lo apto a um determinado fim. Para várias culturas, há a comprovação dos efeitos positivos do cultivo mínimo, reduzido ou plantio direto sobre o preparo convencional do solo, principalmente quando associados ao uso de plantas de cobertura de solo. Dentre os efeitos positivos advindos desses sistemas tem-se a melhoria das características físicas do solo devido ao aumento na infiltração de água no solo (FRANZLUEBBERS, 2002).

Os sistemas mais sustentáveis devem proporcionar boa cobertura do solo durante o ano todo, apresentando disponibilidade de resíduos sobre o solo, que pode ser obtido com a utilização de plantas de cobertura que alcancem elevada produção de resíduos, por um maior tempo e com menor taxa de decomposição. Alguns trabalhos têm demonstrado o efeito de cobertura ou adubação verde sobre a mandioca, em diferentes tipos de preparo de solo, como aqueles de Gabriel Filho et al. (2000) que verificaram que a produtividade de raízes não foi afetada pelo não revolvimento do solo, após adubação com ervilhaca e aveia e de Otsubo et al. (2008) que verificaram melhoria em diferentes fatores de produção da mandioca quando cultivado sobre diferentes coberturas de solo. A adoção de sistemas que mantém na superfície do solo os resíduos de culturas de cobertura na superfície do solo pode constituir uma alternativa tecnicamente viável, sob ponto de vista de sustentabilidade produtiva para a cultura da mandioca.

O objetivo deste trabalho foi comparar o efeito de diferentes formas de preparo de solo e o controle ou não de plantas invasoras sobre os fatores agronômicos e de produção da mandioca.

O experimento foi conduzido no período 2000/2002, no município de Glória de Dourados,

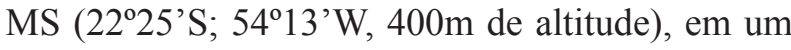
Argissolo Vermelho distrófico, de textura arenosa. O clima de ocorrência, conforme Köppen, é do tipo Aw, com estação quente e chuvosa no verão e moderadamente seca no inverno. A análise química 
do solo, indicaram: $\mathrm{pH}\left(\mathrm{CaCl}_{2}\right) 4,57 ; 1,9 \mathrm{ppm}$ de P; 50 ppm de $\mathrm{K}^{+}$; 0,8 meq $100 \mathrm{~cm}^{-3}$ de Ca; 0,6 meq $100 \mathrm{~cm}^{-3}$ de $\mathrm{Mg} ; 2,47$ meq $100 \mathrm{~cm}^{-3}$ de $\mathrm{H}^{+}+\mathrm{Al}^{3+} ; 2,0 \%$ de M.O. Em junho de 2000 realizou-se o preparo de solo, através de passagem de uma grade aradora e uma niveladora, para posterior plantio da aveia preta (Avena strigosa, Schreb). Não foi realizado nenhum tipo de corte ou dessecação da aveia, deixando que essa completasse seu ciclo vegetativo. As parcelas experimentais que posteriormente seriam ocupadas com o tratamento do sistema de preparo de solo convencional para mandioca, foram deixadas em pousio. Em novembro do mesmo ano, realizou-se o plantio da mandioca (cv. IAC 15) sob a forma de plantio direto com cobertura de palha de aveia e em área de vegetação espontânea composta basicamente por Brachiaria brizantha preparada convencionalmente, por meio de uma ração e duas gradagens. O plantio foi realizado com uso de plantadeira mecanizada provida de discos para facilitar o corte da massa seca de aveia. A profundidade de plantio foi de $0,10 \mathrm{~m}$. A distância entre as manivas na linha de plantio foi de $0,70 \mathrm{~m}$ e entre linhas de $0,90 \mathrm{~m}$. Para os dois sistemas de cultivos, utilizou-se $330 \mathrm{~kg} \mathrm{ha}{ }^{-1}$ de fertilizante mineral NPK (04-20-20) no sulco de plantio. As parcelas experimentais foram compostas por 6 linhas com 14 plantas cada. Como área útil utilizaram-se as duas linhas centrais com 12 plantas úteis por linha, eliminando-se as duas primeiras de cada lado das parcelas. O delineamento experimental utilizado foi o de blocos casualizados com seis repetições. Os tratamentos foram o cultivo da mandioca em: sistema convencional de preparo de solo na área em pousio e com controle de plantas daninhas (PC), plantio direto da mandioca sobre a palhada da aveia com controle de plantas daninhas com herbicida (PDcc) e plantio direto da mandioca sobre a palhada de aveia sem o controle de plantas daninhas (PD-sc). O herbicida utilizado foi o glifosato, na dose de 3,0 1 $\mathrm{ha}^{-1}$. A colheita do experimento foi realizada aos 14 meses de idade quando foram avaliadas as seguintes características: altura de planta (AP): medida a partir do nível do solo até o broto terminal de cada planta, por ocasião da colheita; altura de primeira ramificação (ALTPR): medida a partir do nível do solo até a primeira ramificação verificada na rama; massa fresca da parte aérea (MPA): massa da parte aérea (folhas e rama); massa fresca de cepa (MC); massa fresca de raiz (MR); número de raízes (NR); teor de amido (TA): obtido conforme metodologia da balança hidrostática e índice de colheita (IC): relação entre massa de raízes tuberosas e a massa total das plantas (massa de raiz + massa da parte aérea + massa de cepa).

Os dados foram submetidos a análise de variância e as médias, ao teste de Tukey a 5\% de probabilidade. Utilizou-se a correlação de Pearson para as variáveis estudadas.

Os dados referentes à altura de planta (AP), altura de primeira ramificação (APR), massa fresca de parte aérea (MPA) e massa fresca de cepa (MC) são apresentados na Tabela 1 . Com relação à $\mathrm{AP}$, foram verificadas diferenças significativas entre os tratamentos, no qual os maiores valores foram observados no PD-sc e PD-cc, embora esse último não tenha se diferenciado do PC. Os valores obtidos nesse trabalho, para todos os tratamentos, superam aquele observado por Sagrilo, Otsubo e Silva (2007) que foram de $2,07 \mathrm{~m}$, para a mesma cultivar e mesmo tipo de solo desse estudo. A AP é uma característica importante uma vez que, associada a ventos fortes, podem provocar ocorrência de acamamento na mandioca.

Não foram observadas diferenças entre os tratamentos quanto a APR, embora os valores obtidos sejam superiores àqueles observados por Sagrilo et al. (2010) quando estudaram o comportamento de IAC 15 em três localidades (média de $0,58 \mathrm{~m}$ ). 
Tabela 1. Valores médios de altura de planta (AP), altura de primeira ramificação (APR), massa fresca de parte aérea (MPA) e massa fresca de cepa (MC) de mandioca (cv. IAC 15), sob diferentes formas de cultivo. Glória de Dourados, MS.

\begin{tabular}{|c|c|c|c|c|}
\hline Tratamentos & $\mathrm{AP}(\mathrm{m})$ & $\mathrm{APR}(\mathrm{m})$ & $\operatorname{MPA}\left(\mathrm{kg} \mathrm{ha}^{-1}\right)$ & $\mathrm{MC}\left(\mathrm{kg} \mathrm{ha}^{-1}\right)$ \\
\hline PD-sc ${ }^{(1)}$ & $2,84 \mathrm{~A}$ & $0,95 \mathrm{~A}$ & $50.430 \mathrm{~A}$ & $13.426 \mathrm{~A}$ \\
\hline PD-cc ${ }^{(2)}$ & $2,77 \mathrm{~A}$ & $0,95 \mathrm{~A}$ & $48.611 \mathrm{~A}$ & 10.744 B \\
\hline $\mathrm{PC}^{(3)}$ & $2,52 \mathrm{~B}$ & $0,88 \mathrm{~A}$ & $42.063 \mathrm{~B}$ & $8.214 \mathrm{C}$ \\
\hline C.V. (\%) & 5,74 & 11,89 & 7,06 & 12,56 \\
\hline
\end{tabular}

Médias seguidas de mesma letra na coluna, não diferem entre si pelo teste de Tukey a 5\% de probabilidade. ${ }^{(1)} \mathrm{PD}$-sc: plantio direto sem controle químico de plantas invasoras; ${ }^{(2)} \mathrm{PD}-\mathrm{cc}$ : plantio direto com controle químico de plantas invasora; ${ }^{(3)} \mathrm{PC}$ : preparo de solo convencional.

Fonte: Elaboração dos autores.

Com relação a MPA, os sistemas de manejo PD-sc e PD-cc apresentaram os maiores valores diferenciando significativamente do PC, Otsubo et al. (2008) observaram igual evidência do plantio direto da mandioca sobre esse quesito quando utilizada a cobertura de milheto. A cobertura do solo reduz as perdas de água por evaporação e mantêm a temperatura do solo em níveis mais baixos, condições essas necessárias para um bom desenvolvimento da parte aérea da mandioca. Segundo Alves (2006), o déficit hídrico afeta mais severamente no período de 1 a 5 meses do plantio, justamente no período de formação de raiz e crescimento foliar. O autor destaca ainda, a importância da mandioca alcançar, o mais rapidamente, o índice de área foliar (IAF) ideal para a produção de fotoassimilados e, assim, promover a partição de matéria seca para o desenvolvimento de todos os órgãos da planta. A mandioca podada desenvolve IAF maior que o não podado (OTSUBO; LORENZI, 2004) o que deve ter contribuído para os resultados observados. A produção da parte aérea é uma característica importante sob aspecto técnico, pois está diretamente relacionada à produção de material propagativo, além da possibilidade de utilização como forragem para alimentação animal.

Quanto à $\mathrm{MC}$ destacou-se o tratamento $\mathrm{PD}-\mathrm{sc}$ que diferiu do PD-cc e do PC, que também diferiram entre si. Foi verificada uma correlação positiva entre a MC e MPA $(r=0,84)$, o que era esperado, uma vez que da cepa, maniva de plantio que se transforma durante o ciclo da cultura, partem as ramas, e nela fixam-se as raízes tuberosas, que constituem em uma estrutura de ligação e sustentação entre a parte aérea e o solo. Apesar da cepa ser uma estrutura que atualmente não apresenta nenhuma utilidade para os produtores, podem ser aproveitadas como fonte de energia mediante queima das mesmas para aquecimento de fornos, caldeiras e outras finalidades.

A raiz da mandioca é o órgão de maior interesse econômico, principalmente, quando o destino é o processamento industrial. Na tabela 2, encontram-se os dados referentes ao número de raízes (NR), massa fresca da raiz (MR), teor de amido (TA) e índice de colheita (IC). Quanto ao NR, os maiores valores foram observados nos tratamentos que envolveram o PD-sc (137.401 raízes ha-1) e PD-cc (125.165 raízes $\left.\mathrm{ha}^{-1}\right)$, apesar desse último não ter se diferenciado do PC (114.252 raízes ha-1 ${ }^{-1}$. O número de raízes é uma característica determinada nas primeiras etapas de crescimento da planta (CEBALLOS; CRUZ, 2002) e uma vez definida, não há o surgimento de novas raízes (LORENZI; DIAS, 1993); qualquer competição por água, luz, nutriente, ocorrência de doenças ou ataques severos de pragas, pode afetar o seu estabelecimento. No PC, durante a fase inicial foi necessária a realização de cinco capinas manuais da Brachiaria brizantha, que, apesar do controle, pode ter influenciado nos números finais do NR. Nos tratamentos PD-sc e PD-cc não foi realizado nenhum controle extra de ervas daninhas. O NR 
pode interferir na produtividade final da mandioca, porém, Cock et al.(1979) citados por Alves (2006), alertam para o fato de que estudos têm indicado que uma redução de até $25 \%$ no número de raízes de reserva não afetam a massa final de raízes. Esse fato explica as MR não terem apresentado diferenças significativas entre os tratamentos. Fey et al. (2007), também utilizando a aveia como cobertura, não observaram diferenças entre o plantio direto e o preparo convencional do solo, porém sobre um Latossolo Vermelho; produção de raiz que se mostrou superior no plantio direto, quando comparado com o convencional, foram observados por Otsubo et al. (2008), quando utilizaram o milheto. como planta de cobertura Entretanto, Pequeno et al. (2007) observaram produtividades superiores para o sistema convencional de preparo de solo utilizando a aveia como cobertura sobre um Latossolo Vermelho.

Tabela 2. Valores médios de número de raiz (NR), massa fresca de raiz (MR), teor de amido (TA) e índice de colheita (IC) de mandioca (cv. IAC 15), sob diferentes formas de cultivo. Glória de Dourados, MS.

\begin{tabular}{clccc}
\hline Tratamentos & $\mathrm{NR}\left(\mathrm{n}^{\circ} \mathrm{ha}^{-1}\right)$ & $\mathrm{MR}\left(\mathrm{kg} \mathrm{ha}^{-1}\right)$ & $\mathrm{TA}(\%)$ & $\mathrm{IC}(\%)$ \\
\hline PD-sc $(1)$ & $137.401 \mathrm{~A}$ & $54.705 \mathrm{~A}$ & $28,35 \mathrm{~B}$ & $46,27 \mathrm{~B}$ \\
$\mathrm{PD}-\mathrm{cc}^{(2)}$ & $125.165 \mathrm{AB}$ & $48.500 \mathrm{~A}$ & $30,40 \mathrm{~A}$ & $45,56 \mathrm{~B}$ \\
$\mathrm{PC}^{(3)}$ & $114.252 \mathrm{~B}$ & $53.151 \mathrm{~A}$ & $28,13 \mathrm{~B}$ & $50,74 \mathrm{~A}$ \\
\hline C.V. $(\%)$ & 11,03 & 7,89 & 3,23 & 5,81 \\
\hline
\end{tabular}

Médias seguidas de mesma letra na coluna, não diferem entre si pelo teste de Tukey a 5\% de probabilidade. (1)PD-sc: plantio direto sem controle químico de plantas invasoras; ${ }^{(2)} \mathrm{PD}-\mathrm{cc}$ : plantio direto com controle químico de plantas invasora; ${ }^{(3)} \mathrm{PC}$ : preparo de solo convencional.

Fonte: Elaboração dos autores.

Essa divergência de resultados entre os poucos trabalhos realizados com a cultura da mandioca relacionados ao plantio direto e à cobertura do solo, demonstram a necessidade de maiores estudos sobre o tema.

Com relação ao TA, observou-se que o PD-cc apresentou os maiores teores, diferenciando dos demais tratamentos. Esse resultado indica que apesar da concorrência da reinfestação da aveia, que não foi controlada, e a vegetação espontânea observadas nos tratamentos PD-sc e PC, respectivamente, com a mandioca, não tenham influenciado em alguns fatores, como a MR, alterou o acúmulo final de amido nas raízes. Carvalho, Peressin e Araújo (2006) destacam a redução no acúmulo de matéria seca total, da qual se encontra o amido, entre os principais danos causados pela competição das plantas daninhas na cultura da mandioca. Otsubo et al. (2008) observaram os menores valores nos teores de amido no sistema convencional quando comparado com o plantio direto da mandioca sob diferentes plantas de cobertutra (milheto, sorgo granífero e mucuna cinza). O TA é uma característica importante para o rendimento industrial e para o produtor em si, pois, constitui em referência para pagamento.

O maior IC foi observado no PC que se diferenciou dos demais, o que corrobora com os resultados observados por Otsubo et al. (2008), porém, os valores observados nos tratamentos em que não realizaram o preparo de solo se assemelham àqueles observados por Otsubo et al. (2009), para o mesmo material, quando cultivado sob preparo convencional de solo em uma área de cerrado.

A altura de plantas, produção de massa de parte aérea e teor de amido das raízes de mandioca são influenciados pelo sistema de preparo do solo e pela cobertura proporcionada pela palhada da aveia.

O plantio direto da mandioca sobre a palhada de aveia é uma alternativa sustentável para a produção da mandioca. 


\section{Referências}

ALVES, A. A. C. Fisiologia da mandioca. In: SOUZA, L. da S.; FARIAS, A. R. N.; MATTOS, P. L. P. de; FUKUDA, W. M. G. (Ed.). Aspectos socioeconômicos e agronômicos da mandioca. Cruz das Almas: Embrapa Mandioca e Fruticultura, 2006. p. 138-169.

CARVALHO, J. E. B. de; PERESSIN, V. A.; ARAÚJO, A. M. de A. Manejo e controle de plantas daninhas. In: SOUZA, L. da S.; FARIAS, A. R. N.; MATTOS, P. L. P. de; FUKUDA, W. M. G. (Ed.). Aspectos socioeconômicos e agronômicos da mandioca. Cruz das Almas: Embrapa Mandioca e Fruticultura, 2006. p. 560-590.

CEBALlOS, H.; CRUZ, G. A de la. Taxonomia y morfología de la yuca. In: OSPINA, B.; CEBALLOS, H. La yuca en el tercer milenio. Sistemas modernos de producción, procesamiento, utilización y comercialización. Cali, Colombia: Centro Internacional de Agricultura Tropical: Consorcio Latinoamericano y del Caribe de Apoyo a la Investigación y Desarrollo de la Yuca: Proyecto IP-3 Mejoramiento de Yuca, 2002. p. 17-33.

CONTI, C.; FEY, E. Influência de volumes de solo revolvidos no sulco, variedades e tipos de corte das manivas sobre o estabelecimento da cultura da mandioca em sistema plantio direto. Revista Raizes e Amidos Tropicais, Botucatu, v. 3, out. 2007. Disponível em: $<$ http://www.cerat.unesp.br/revistarat/volume3/artigos/ 104\%20Cristiano\%20Conti.pdf.>. Acesso em: 25 ago. 2010.

FEY, E.; CONTI, C.; SOUZA, J. H. de; GOBBI, F. C.; FURLAN, F. Influência do manejo do solo sobre a produtividade da mandioca de um e dois ciclos. Revista Raizes e Amidos Tropicais, Botucatu, v. 3, out. 2007. Disponível em: <http://www.cerat.unesp.br/revistarat/ volume $3 /$ artigos $/ 105 \% 20$ Laercio $\% 20$ emerson $\% 20$ fey. pdf. $>$. Acesso em: 25 ago. 2010.

FRANZLUEBBERS, A. J. Water infiltration and soil structure related to organic matter and its stratification with depth. Soil \& Tillage Research, Amsterdam, v. 66, n. 2, p. 197-205, 2002.

GABRIEL FILHO, A.; PESSOA, A. C. S.; STROHHAECKER, L.; HELMICH, J. J. Preparo convencional e cultivo mínimo do solo na cultura da mandioca em condições de adubação verde com ervilhaca e aveia. Ciência Rural, Santa Maria, v. 30, n. 6, p. $953-$ 957, 2000.

LORENZI, J. O.; DIAS, C. A. de C. Cultura da mandioca. Campinas: CATI, 1993. 41p. (Boletim técnico, 211).
OTSUBO, A. A.; BRITO, O. R.; MERCANTE, F. M.; OTSUBO, V. H. N.; GONÇALVES, M. A.; TELLES, T. S. Desempenho de cultivares elites de mandioca industrial em área de cerrado do Mato Grosso do Sul. Semina: Ciências Agrárias, Londrina, v. 30, p. 11551162, 2009. Suplemento 1.

OTSUBO, A. A.; MERCANTE, F. M.; SILVA, R. F. da; BORGES, C. D. Sistemas de preparo do solo, plantas de cobertura e produtividade da cultura da mandioca. Pesquisa Agropecuária Brasileira, Brasília, v. 43, n. 3, p. 327-332, mar. 2008.

OTSUBO, A. A.; LORENZI, J. O. (Ed.). Cultivo da mandioca na região centro sul do Brasil. Dourados: Embrapa Agropecuária Oeste; Cruz das Almas: Embrapa Mandioca e Fruticultura, 2004. 116 p. (Sistema de Produção, 6).

PEQUENO, M. G.; VIDIGAL FILHO, P. S.; PINHEIRO NETO, R.; KVITSCHAL, M. V. Efeito de três sistemas de preparo de solo sobre a rentabilidade econômica da mandioca (Manihot esculenta Crantz). Acta Scientiarum Agronomy, Maringá, v. 29, n. 3, p. 379-386, 2007.

SAGRILO, E.; OTSUBO, A. A.; SILVA, A. de S. Desempenho produtivo de genótipos de mandioca no Vale do Ivinhema, MS. Revista Raizes e Amidos Tropicais, Botucatu, v. 3, out. 2007. Disponível em: <http://www. cerat.unesp.br/revistarat/volume3/153\%20Edvaldo $\% 20$ Sagrilo.pdf.>. Acesso em: 18 abr. 2010.

SAGRILO, E.; VIDIGAL FILHO, P. S.; OTSUBO, A. A.; SILVA, A. de S.; ROHDEN, V. da S. Performance de cultivares de mandioca e incidência de mosca branca no Vale do Ivinhema, Mato Grosso do Sul. Revista Ceres, Viçosa, v. 57, n. 1, p. 87-94, 2010.

SOUZA, L. D.; MOTA, P. P.; SOUZA, L. da S.; SANTOS, C. V. dos; PEREIRA, B. L. da; FIGUEIREDO, G. H. S. Potencial d água no solo sob diferentes sistemas de preparo de solo na cultura da mandioca. Revista Raízes e Amidos Tropicais, Botucatu, v. 3, out. 2007. Disponível em: <http://www.cerat.unesp.br/revistarat/ volume3/ artigos $/ 116 \% 20$ Laercio\%20duarte\%20souza.pdf.>. Acesso em: 25 ago. 2010.

SOUZA, L. D.; SOUZA, L. da S.; GOMES, J. de C. Exigências edáficas da cultura da mandioca. In: SOUZA, L. da S.; FARIAS, A. R. N.; MATTOS, P. L. P. de; FUKUDA, W. M. G. (Ed.). Aspectos socioeconômicos e agronômicos da mandioca. Cruz das Almas: Embrapa Mandioca e Fruticultura, 2006. p. 170-214. 